\title{
Modernização e segregação: a pesca artesanal no projeto nacional-desenvolvimentista
}

\author{
Modernization and segregation: artisanal fishing in the \\ national-developmental
}

\author{
Modernización y segregación: pesca artesanal em
} desarrolismo nacional

\section{Carolina de Oliveira e Silva Cyrino}

ORCID: 0000-0001-6951-581X

Doutoranda em Sociologia na Universidade Federal do Rio Grande do Sul, UFRGS, Brasil. Mestre em Ciências Sociais pela Universidade Federal do Espírito Santo (UFES). Bolsista da Coordenação de Aperfeiçoamento de Pessoal de Nível Superior (CAPES). E-mail: carolinacyrino.ufes@gmail.com

\section{Resumo}

Este artigo analisa aspectos do processo de modernização da pesca no Brasil e sua relação com a segregação da atividade artesanal, durante a gestão da extinta Superintendência de Desenvolvimento da Pesca - SUDEPE, na década de 1970. Neste período, os ideais nacional-desenvolvimentistas alcançaram a economia nacional, e na política pesqueira fortaleceram-se através de estratégias de modernização da atividade e fomento às indústrias de pesca. Analisaremos algumas estratégias e discursos da SUDEPE - por meio de análise de documentos institucionais e dispositivos legais - no desenvolvimento de políticas modernizadoras que tinham como promessa a "evolução do setor pesqueiro", entretanto, preterindo a atividade artesanal no projeto de desenvolvimento nacional.

Palavras-chave: Nacional-desenvolvimentismo; Modernização; Política Pesqueira; Pesca artesanal. 


\section{Introdução}

As trajetórias da política pesqueira no Brasil foram marcadas pelo ideal de modernização da atividade. O fomento à industrialização da pesca e adoção de técnicas modernas foram premissas assumidas pelo Estado ainda nas primeiras ações de regulação da atividade no início do século XX, com a criação das colônias de pesca pela Marinha do Brasil. Ao longo desse processo de modernização, a atividade artesanal foi preterida em prol da pesca de grande escala e procedimentos considerados modernos que contribuíssem para o desenvolvimento nacional. Esses direcionamentos repercutem, ainda hoje, em um processo de desigualdade e exclusão dos pescadores artesanais. Não somente pela apropriação de territórios e recursos pesqueiros, como também na segregação da atividade e reprodução social dessa população.

Nas ciências sociais brasileiras ${ }^{1}$, existem estudos que se dedicaram a pesquisar como as populações pesqueiras foram atingidas pela escolha de um projeto modernizador do Estado, sustentadas por um ideário desenvolvimentista, em que ora os seus modos de vida e trabalho eram afirmados como incompatíveis com este ideal de modernização, ora eram aspectos negligenciados.

A discussão que faremos está voltada a um período particular dessa trajetória, marcado pelo auge do projeto nacional-desenvolvimentista, período de forte promoção do Estado à industrialização da economia e expansão do mercado interno, além da exploração de áreas e recursos naturais. A premissa de conduzir o país ao progresso, através de um projeto de desenvolvimento nacional, alcançou diversos setores econômicos no país, incluindo a pesca, um setor que tem sua grande força de trabalho através da pesca artesanal.

Este artigo analisa aspectos do processo de modernização do setor pesqueiro no Brasil e sua relação com a segregação da pesca artesanal, na década de 1970, em que a gestão foi assumida pela extinta Superintendência de Desenvolvimento da Pesca - SUDEPE, com destaque no incentivo à expansão da exploração dos recursos pesqueiros, com fomento à criação e desenvolvimento das indústrias de pesca no país. Nesse contexto, amalgamados ao projeto nacional-desenvolvimentista em curso, embora com o anúncio de proporcionar aos pescadores os benefícios da modernização da atividade, a pesca artesanal passou a ser considerada um entrave para o processo de modernização do país, e os pescadores foram utilizados como força braçal das indústrias de pesca.

\footnotetext{
${ }^{1}$ Destaque para os trabalhos de Silva (2015); Ramalho (2014; 2002); Diegues (1999; 1983); Dias Neto (2015); Brito (1999); Maldonado (1994; 1986), entre outros.
} 
A SUDEPE assumiu o projeto desenvolvimentista que estava em curso. Trazemos na primeira parte deste artigo, a discussão sobre o nacional-desenvolvimentismo para compreender como o Estado passou a adotar determinadas orientações na regulação da atividade nesse contexto. O que seria esse projeto de desenvolvimento nacional? E para que/quem ele estaria sendo direcionado? Estas indagações podem nos auxiliar na compreensão das ações da política pesqueira assumidas no período e suas repercussões na regulação da pesca artesanal. As ações da SUDEPE estavam inseridas no projeto de desenvolvimento nacional no Brasil que, segundo o I Plano Nacional de Desenvolvimento PNP (Brasil, 1971:14) tinha como diretriz "transformar o Brasil em uma nação desenvolvida, [...] através da criação de uma economia moderna, criativa e dinâmica”.

Analisaremos neste trabalho algumas estratégias e discursos da SUDEPE no desenvolvimento de ações políticas modernizadoras que tinham como promessa a evolução do setor pesqueiro. Não se trata aqui de estabelecer um histórico das ações da SUDEPE na política pesqueira, mas de trazer à discussão aspectos do processo de modernização do setor pesqueiro no Brasil e sua relação com a segregação da pesca artesanal, na década de 1970.

$\mathrm{Na}$ segunda seção deste trabalho tomamos como análise o Plano Nacional de Desenvolvimento da Pesca - PNDP (1975-1979), além de recorrermos a dispositivos legais da época. A análise desse PNDP, publicado em 1980, deve-se ao fato de, especificamente a parte I “Aspectos Institucionais do Desenvolvimento da Pesca no Brasil”, apresentar uma retrospectiva das trajetórias da política pesqueira até o final dos anos 1970, década analisada neste trabalho. Correlacionaremos este conteúdo com o discurso de modernização do setor pesqueiro, marcado nas trajetórias da política pesqueira no Brasil e a classificação da atividade artesanal nesse projeto de desenvolvimento nacional. A escolha modernizadora da atividade pelo Estado é anunciada como benefício às populações pesqueiras.

\section{Modernização e desenvolvimentismo como projeto nacional}

A análise do desenvolvimentismo é um ponto fundamental para o estudo do processo de constituição e formação da sociedade brasileira (Cepêda, 2012a), e neste trabalho colaborará para o entendimento de como o Estado assumiu determinadas orientações ao identificar a pesca e os pescadores nesse contexto político. Cepêda reconhece a amplitude da discussão em torno do termo desenvolvimento, considerando os vários níveis de debate intelectuais e políticos que o atravessam. Partiremos então da definição concebida por essa socióloga, ao compreender que o ideal de mudança estaria no cerne da sua dimensão 
histórica, e a adição do sufixo ismo pressupõe o aspecto de movimento, processo. Desse modo, o desenvolvimentismo pode ser definido como “[...] um projeto de transformação social profunda, operada politicamente de maneira racional e orientada pelo Estado, vinculando economia e avanço social” (Cepêda, 2012b:79). Neste cenário, o Estado ganha destaque no processo de desenvolvimento, com o papel de promover as transformações que conduziriam a sociedade a uma ordem industrial moderna.

O processo de modernização da economia nacional expandia-se entre os estados da federação, implantando grandes projetos industriais, apostando na integração do capitalismo nacional e internacional, na transformação, em curto período, do predomínio agroexportador, para o modelo secundário-exportador, centrado em commodities industriais de produção de larga escala (Siqueira, 2010).

Esses grandes projetos foram responsáveis por altas movimentações financeiras, pautados, por exemplo, na expansão portuária, exploração de minério de ferro, produção de celulose, além da extração de petróleo. Entretanto, o desenvolvimento social não teve a mesma atenção investida, e o país sofreu graves consequências desse acentuado processo de modernização, “os grandes projetos de industrialização e de expansão portuária foram processados sem qualquer preocupação com expressões territoriais tradicionais ou mesmo com preceitos ambientais" (Santos, 2015:170). Houve a queda sensível da qualidade de vida das regiões que sofreram as transformações decorrentes do processo industrial, associada aos problemas típicos das grandes aglomerações: a sobrecarga da infraestrutura e dos serviços de atendimento ao público, aumento da criminalidade, saturação do sistema viário e segregação socioespacial.

Comum na América Latina, o projeto nacional-desenvolvimentista apropria-se dos ideais de modernização a fim de atingir seus objetivos de controle econômico e social. Nessa compreensão, García Canclini (2015) afirma que os avanços modernos em nosso continente não se completaram e nem atenderam a todos e, desse modo, questiona o ideal de modernidade como objetivo central a ser alcançado pelos países latino-americanos, defendido por segmentos políticos, econômicos, tecnológicos.

Não tivemos uma industrialização sólida, nem uma tecnificação generalizada da produção agrária, nem uma organização sociopolítica baseada na racionalidade formal e material que, conforme lemos de Kant a Weber, teria transformado em senso comum no Ocidente, o modelo de espaço público onde os cidadãos conviveriam democraticamente e participariam da evolução social. Nem o progressismo evolucionista, nem o racionalismo democrático foram, entre nós, causas populares (García-Canclini, 2015:24). 
O projeto de desenvolvimento nacional, com o discurso de transformar o país em uma nação moderna, respondia aos interesses de determinados grupos, e que os custos de tal campanha geraram consequências que atingiram especialmente as camadas mais pobres da população. É nesse aspecto que García Canclini (2015:25) afirma que "a modernidade é vista então como uma máscara. Um simulacro urdido pelas elites e pelos aparelhos estatais”. Nesse intento, as ideologias modernizadoras no período desenvolvimentista acentuaram a ideia de que a modernização acabaria com as formas tradicionais e crenças. Essa orientação vai ser sustentada ao longo da gestão da SUDEPE, na qual, o ideal moderno é colocado como uma promessa libertadora e progressista.

O elemento central dessa discussão é a existência de impedimentos para o pleno desenvolvimento dos processos de produção e modernização em países entendidos como "retardatários". Nesta dinâmica, enquanto as economias centrais avançavam para a etapa mais complexa do capitalismo industrial, o desenvolvimento das sociedades periféricas era limitado e, nesse aspecto, "o atraso aparece, então, como um capitalismo inconcluso, incompleto: como expressão de subdesenvolvimento" (Cepêda, 2012a:80).

Essa euforia pela modernização nesse período tinha por ideal a universalização do desenvolvimento econômico alcançado pelos países que lideraram a revolução industrial, entretanto, esse desenvolvimento não se deu da mesma forma nos países periféricos. Ao analisar essa relação centro-periferia, Furtado (1986) esclarece que se buscou generalizar a forma de desenvolvimento alcançado nos países centrais, não se atentando aos contextos sociais e nem as consequentes mudanças no mundo físico.

Nesse contexto surgiram novas compreensões no campo das Ciências Sociais acerca do desenvolvimento da modernidade latino-americana. Costa (2017) explica que a partir das décadas de 1950 e 1960 a teoria da modernização passa a ser confrontada, ganhando relevo a teoria da dependência, na investigação sobre a modernidade na América Latina, que propõe uma análise a partir das interdependências entre desenvolvimento e subdesenvolvimento.

\footnotetext{
Com isso, corrige-se a teoria da modernização onde ela estabelece que a modernidade se origina na Europa e só depois se expande globalmente. Para os autores da teoria da dependência, a modernidade está relacionada, desde seus princípios, com o estreitamento dos entrelaçamentos entre Europa e o resto do mundo (Costa, 2017:486).
}

Essa compreensão de uma modernidade dependente, como classifica Costa (2017), trouxe diferentes abordagens acerca da modernidade na América Latina, a partir de duas variantes, a reformista e a marxista. 
O viés reformista analisa a questão da dependência como algo a ser solucionado nacionalmente, tem como uma das suas grandes referências no Brasil o sociólogo Fernando Henrique Cardoso, que viria a assumir a Presidência da República décadas depois, eleito em dois mandatos (1995 a 2003). No trabalho Dependência e Desenvolvimento na América Latina, publicado originalmente em 1970, Cardoso e Falleto (1979) ao analisarem a internalização do mercado como novo caráter de dependência, afirmam que as decisões políticas tomadas no âmbito nacional possibilitariam a determinação econômica, reorganizando as relações centro-periferia do desenvolvimento capitalista.

A novidade da hipótese não está no reconhecimento da existência de uma dominação externa - processo óbvio - mas na caracterização da forma que ela assume e dos efeitos distintos, com referência às situações passadas, desse tipo de relação de dependência sobre as classes e o Estado. [...] A formação de uma economia industrial na periferia do sistema capitalista internacional minimiza os efeitos da exploração tipicamente colonialista e busca solidariedades não só nas classes dominantes, mas no conjunto dos grupos sociais ligados à produção capitalista moderna: assalariados, técnicos, empresários, burocratas e etc. (Cardoso; Faleto,1979:14).

Essa compreensão influenciou e ainda influencia tanto decisões políticas como análises reformistas. De outro lado, o viés marxista vai questionar essa proposta da questão da dependência ser solucionada nacionalmente, considerando o seu caráter global. Na obra Democracia e Socialismo no Capitalismo Dependente, Theotônio dos Santos afirma que "o que primeiro caracteriza uma estrutura dependente é a própria concentração econômica, ligada ao fenômeno da superexploração da força de trabalho e a grande concentração de capital" (1991:49). Nesse sentido, Santos (1991) explica que essa vertente analisa de forma dialética o fenômeno do desenvolvimento capitalista e as estruturas internas dos países que são objeto desse processo de expansão, como os latino-americanos. Desse modo, confronta a forma imperialista que engendrou o desenvolvimento internacional do capitalismo através, por exemplo, do controle das matérias-primas e da hegemonia do capital financeiro que, na expansão desse desenvolvimento capitalista, cria uma situação de dependência. Nesse mesmo entendimento, a superexploração do trabalho está no centro da interpretação sobre a natureza do capitalismo periférico latino americano, na obra de Ruy Mauro Marini (2000). Costa (2017) ao trazer a análise sobre a obra de Marini, em Dialética da Dependência, esclarece que:

Marini compreende as estruturas de acumulação de capital na Europa e na América Latina como interligadas de uma tal maneira que excedentes econômicos nesta última só podem ser atingidos via superexploração da força de trabalho local, o que, por sua vez, impede a formação de mercados internos na região. Além disso, em 
virtude da dependência latino-americana diante das nações centrais no concernente a capitais e à tecnologia, mesmo uma industrialização eficazmente baseada no modelo de substituição de importações levava a que a própria lógica da dependência se aprofundasse (Costa, 2017:487).

Desse modo, esse modelo de desenvolvimento no país passa a privilegiar o alto consumo de determinados segmentos, provocando crescente concentração de capital, ao passo que também promove graves desigualdades sociais e a exploração de recursos naturais. Assim, "característica mais significativa do modelo brasileiro é a sua tendência estrutural para excluir a massa da população dos benefícios da acumulação e do progresso técnico" (Furtado, 1986:109).

Conforme poderemos ver no decorrer da análise, a SUDEPE vai direcionar a sua prática à priorização do desenvolvimento da indústria pesqueira e, nesse caso, os benefícios dessa modernidade não alcançavam os pequenos pescadores e suas comunidades. Ao contrário, passou-se a realizar a exploração dos recursos pesqueiros e à desvalorização da atividade artesanal. Recorremos a tese de Furtado (1983), para compreender como as ações políticas direcionadas aos pescadores não conseguiram atentar para as desigualdades geradas pelo próprio projeto desenvolvimentista. Ora, os benefícios anunciados por esse projeto de modernização não são alcançáveis pelas comunidades de pescadores artesanais, e ao mesmo tempo, rejeita seus modos de vida e trabalho. Por esse caráter excludente e elitista é que Furtado defende que ideia desse desenvolvimento econômico é um mito:

[...] a ideia de que os povos pobres podem algum dia desfrutar das formas de vida dos atuais povos ricos - é simplesmente irrealizável. Sabemos agora de forma irrefutável que as economias da periferia nunca serão desenvolvidas, no sentido de similares às economias que formam o atual centro do sistema capitalista. Mas, como negar que essa ideia tem sido de grande utilidade para mobilizar os povos da periferia e levá-los a aceitar enormes sacrifícios, para legitimar a destruição de formas de culturas arcaicas, para explicar e fazer compreender a necessidade de destruir o meio físico, para justificar formas de dependência que reforçam o caráter predatório do sistema produtivo. [...] Cabe, portanto, afirmar que a ideia de desenvolvimento econômico é um simples mito (Furtado, 1983:75, destaques do autor).

É no auge do projeto desenvolvimentista que é criada a SUDEPE, cuja base, como já afirmamos, era a aposta no fomento de uma indústria de base pesqueira e tecnificação do setor. Aliada a esse modelo de desenvolvimento, a autarquia dedicou-se a promoção da industrialização da pesca através dos incentivos fiscais, direcionando suas ações para a ampliação dos estoques pesqueiros. Essa orientação é reforçada em sua análise institucional ao avaliar que os recursos pesqueiros eram poucos explorados, considerando a extensão 
litorânea da costa brasileira, portanto, a industrialização do setor seria fundamental (Sudepe,1980).

\section{$O$ fomento à indústria pesqueira: expansão dos recursos pesqueiros e a desvalorização da atividade artesanal}

A Superintendência de Desenvolvimento da Pesca - SUDEPE, autarquia federal subordinada ao Ministério da Agricultura, criada através da Lei Delegada 10, de outubro de 1962 (Brasil, 1962), assumiu um ambicioso projeto de desenvolvimento do setor, por meio da sua industrialização, incentivos fiscais e ampliação dos estoques pesqueiros, através do fomento à pesca de grande escala.

Importa destacar que, neste período, a política pesqueira já havia alcançado grande visibilidade com a criação das colônias de pesca pela Marinha do Brasil, através da missão do Cruzador José Bonifácio entre 1919 a 1923, que tinha a premissa de instruir e sanear as populações pesqueiras no Brasil, modernizar a atividade artesanal, considerada obsoleta, bem como os pescadores, que foram classificados como atrasados e incivilizados (Cyrino, 2019).

A própria SUDEPE faz uma menção honrosa ao trabalho militar realizado, evidenciando que durante os quatro anos da expedição da Missão, os militares percorreram o litoral brasileiro cadastrando mais de 100.000 pescadores e organizando-os em colônias cooperativas com espaço para serviços de ensino e saúde, dos quais resultou o "Serviço de Pesca e Saneamento do Litoral”, em 1923: "É nesse trabalho pioneiro, de Frederico Villar, que são estabelecidas as bases definitivas para o desenvolvimento da pesca no Brasil, e de uma orientação para uma futura ação de governo" (Sudepe, 1980:11).

Assim, foi por meio das ações empreendidas pela Marinha do Brasil que se deu início às primeiras estratégias de regulação da pesca no país. Já a partir de 1912, o país vivenciava a expectativa do progresso desenvolvimentista urbano-industrial e, neste cenário, a pesca chamou atenção das elites empresariais, que apostaram na modernização do setor, através da sua industrialização. As ações promovidas pela instituição militar estavam alinhadas a essa perspectiva e visavam ao controle e expansão da atividade pesqueira. Antes de iniciar a Missão, o comandante Frederico Villar percorreu colônias de pesca estrangeiras, em especial no continente europeu, a fim de trazer para o Brasil um projeto de modernização da pesca, para valorizar o vasto litoral brasileiro e os recursos pesqueiros entregues, segundo o mesmo, a miseráveis pescadores. Villar registrou as memórias da Missão do Cruzador José Bonifácio e foi aplaudido pelo Estado como um apóstolo civilizador. A criação das colônias de pesca no 
Brasil revelou-se um projeto civilizatório, de classificação da atividade artesanal como obsoleta e entrave para o progresso do país, e os pescadores e suas comunidades como pessoas alheias às conquistas da civilização e do trabalho ${ }^{2}$ (Villar, 1945).

A instalação das colônias de pesca possibilitou ao Estado o controle dos recursos pesqueiros e dos trabalhadores da pesca. Assim como para a Marinha brasileira, a modernização e a formação técnica para a pesca também foram preocupações do Ministério da Agricultura que assumiu a gestão do setor pesqueiro através da Divisão de Caça e Pesca $^{3}$,dando continuidade ao trabalho desenvolvido pela instituição naval, nas décadas seguintes, em especial no período do Estado Novo. Com a determinação da obrigatoriedade de filiação de todos os pescadores às colônias, através do Código de Pesca ${ }^{4}$, o Estado passou a ter maior controle dos recursos pesqueiros e dos trabalhadores da pesca, incluindo o fornecimento de dados relativos à quantidade, qualidade e lugar em que eram praticadas as atividades pesqueiras, estando os pescadores sujeitos a sanções disciplinares ${ }^{5}$ que variavam do pagamento de multas, suspensão de matrículas, licenças e até prisões, conforme a legislação penal vigente.

A influência da Marinha exercia-se nas colônias, enquanto a do Ministério da Agricultura na criação e gestão de leis. Desse modo, a instituição naval se estabeleceu como uma propulsora força da intervenção estatal de conduzir os pescadores à modernização das suas atividades e abrir caminhos para a industrialização do setor na trajetória desenvolvimentista no país. Isso propulsionou a adoção de novas orientações da política pesqueira para os pescadores artesanais a partir da década de 1960, com a criação da SUDEPE.

\footnotetext{
${ }^{2}$ Para aprofundamento histórico sobre a Missão do Cruzador José Bonifácio, destaco os trabalhos de Bentes Filho (2018) e Callou (1994). Os registros dessa missão militar foram publicados pelo comandante Frederico Villar vinte anos após sua conclusão, em 1945, durante o Estado Novo. Neste mesmo período, foi publicado o "Manual de Patrão da Pesca", compêndio organizado por Villar, que reúne narrativas, códigos disciplinares e instrução técnica para modernização da atividade. Para discussão da relação desses registros militares com as trajetórias da política pesqueira no Brasil, ver Cyrino (2018). Considerações sobre a discussão dessa empreitada militar enquanto projeto civilizatório é possível encontrar em Cyrino (2019).

${ }^{3}$ Em 1933 a pesca passa a ser regulamentada pelo Ministério da Agricultura e o Serviço da Pesca e Saneamento do Litoral, resultante da Missão, é extinto e substituído pelo Departamento de Indústria Animal - Divisão de Caça e Pesca (Villar, 1945).

${ }^{4}$ Durante a vigência da Divisão de Caça e Pesca é promulgado o Código de Caça e Pesca (Brasil, 1934), classificando a pesca em duas categorias: marítimas e de interior (em águas doces sem contato com o mar). Neste Código, o Ministério da Agricultura passa a ser responsável por todo o serviço de administração, gestão, fiscalização e execução dos dispositivos legais. Em 1938, o referido Código é atualizado, sendo denominado Código de Pesca (Brasil, 1938), com ênfase ao que dispõe sobre as colônias e fiscalização do uso de aparelhos, captura de espécie, documentação, incluindo sanções disciplinares.

${ }^{5}$ Ramalho (2014) ressalta que a política que estava sendo conduzida nesse período mantinha o viés policialesco sobre a vida política e de trabalho dos pescadores. Essas orientações firmaram raízes profundas na forma com a qual as colônias de pescadores passaram a ganhar destaque, como frente de execução da política de Estado, ao mesmo tempo de caráter assistencialista e disciplinador.
} 
A Divisão de Caça e Pesca, de acordo com a análise da SUDEPE, deu continuidade ao trabalho desenvolvido pela Marinha brasileira, em especial na expansão dos serviços de promoção social, com a instalação de serviços de saúde aos pescadores registrados nas colônias. Entretanto, a autarquia afirmou que a atuação foi direcionada prioritariamente, no desenvolvimento de pesquisas e capacitação técnica, através da instalação de Postos Experimentais de Biologia e Psicultura, "[...] desenvolvendo atividades de pesquisas no campo da tecnologia do pescado, através da sua unidade de indústria" (Sudepe, 1980:12). Destacando também o direcionamento para a capacitação da mão-de-obra, a fim de atender as novas demandas da pesca, referente à sua modernização.

Embora tenha considerado positivo o trabalho da Divisão de Caça e Pesca na tecnificação do setor, a SUDEPE revelou-se descontente pela permanência ainda de procedências artesanais nas atividades pesqueiras. Segundo a instituição, isso ocorreu devido à “[...] ausência de um mercado organizado, e também pela impossibilidade demonstrada de atender as solicitações que o desenvolvimento urbano-industrial brasileiro requeria" (Sudepe, 1980:15). As deficiências apontadas na avaliação da SUDEPE também ocorreram “[...] por graves problemas de coordenação das atividades pesqueiras, em face de inúmeros órgãos atuantes e da legislação fragmentada". Em decorrência destes entraves, criou-se o Conselho de Desenvolvimento da Pesca - CODEPE, em 1961, a fim de reunir todas as atribuições normativas pesqueiras. Através do Decreto-Lei 50.872, sancionado pelo então presidente Jânio Quadros, o CODEPE ficou responsável pela criação de uma Política Nacional da Pesca, tendo por premissa a industrialização, tecnificação e modernização do setor (Brasil, 1961), evidenciando-se o início da previsão de financiamentos.

Todo esse movimento foi direcionado para a formação de um pequeno grupo da pesca que, posteriormente, seria denominado de pescador industrial (Silva, 2015). Embora a criação do CODEPE, em 1961, deu-se a fim de avocar a regulação da Pesca, é a Superintendência de Desenvolvimento da Pesca, criada no ano seguinte, com a missão de promover a evolução do setor pesqueiro, que assumirá essa fase da política pesqueira, marcada pela forte expansão da indústria pesqueira e financiamentos de empreendimentos de pesca. A Lei Delegada 10 (Brasil,1962), que cria a autarquia subordinada ao Ministério da Agricultura, dispõe que:

Art. $2^{\circ}$ compete à SUDEPE:

I - Elaborar o Plano Nacional de Desenvolvimento da Pesca (PNDP) e promover a sua execução;

II - Prestar assistência técnica e financeira aos empreendimentos de pesca;

III - Realizar estudos, em caráter, permanente, que visem à atualização das leis aplicáveis à pesca ou aos recursos pesqueiros, propondo as providências convenientes; 
IV - Aplicar no que couber, o Código de Pesca e a legislação das atividades ligadas à pesca ou aos recursos pesqueiros;

V - Pronunciar-se sobre pedidos de financiamentos destinados à pesca formulados a entidade oficiais de crédito;

VI - Coordenar programas de assistência técnica nacional ou estrangeira;

VII - Assistir aos pescadores na solução de seus problemas econômico-sociais.

O Plano Nacional de Desenvolvimento da Pesca foi criado com o objetivo de justificar os investimentos do governo federal nos empreendimentos de pesca, definindo seu alcance nos setores básicos em que se concentrem os investimentos públicos. Ressalta-se que a Lei Delegada n.10 não faz menção ao termo "artesanal" ou "pescadores artesanais", embora indique a assistência aos pescadores na "solução de seus problemas econômicos-sociais" medidas realizadas através das colônias de pesca sob controle tutelar do Estado. Também previa analisar as perspectivas dos investimentos privados, com indicação das medidas para incentivá-los. A legislação dava especial atenção à abrangência do PNDP no fomento à tecnificação do setor pesqueiro:

$\S 2^{\circ} \mathrm{O}$ PNDP dará destaque à realização de pesquisas e de experimentos básicos ao desenvolvimento da piscicultura, à organização e expansão da infra-estrutura da pesca, à formação e capacitação de mão-de-obra especializada e à assistência técnica e financeira àqueles que exerçam atividade relacionada com a pesca ou seus produtos.

O período de gestão da SUDEPE (1962-1989) é atravessado pela instauração do regime militar, em 1964, através do golpe deflagrado contra o governo do presidente João Goulart. Essa intervenção militar também deixou suas marcas na política pesqueira e na vida dos pescadores artesanais, permanecendo aliada ao "[...] fortalecimento de políticas autoritárias relacionadas à organização política da categoria” (Ramalho, 2014). Abaixo a capa do PNDP utilizado como análise neste artigo, em que a SUDEPE apresenta a análise institucional da trajetória da política pesqueira.

Figura 1. Plano Nacional de

Desenvolvimento da Pesca (1975 - 1979)

Fonte: Capa do Plano Nacional do Desenvolvimento da Pesca, 1975 - 1979, (Sudepe, 1980). Edição Fotocopiada.

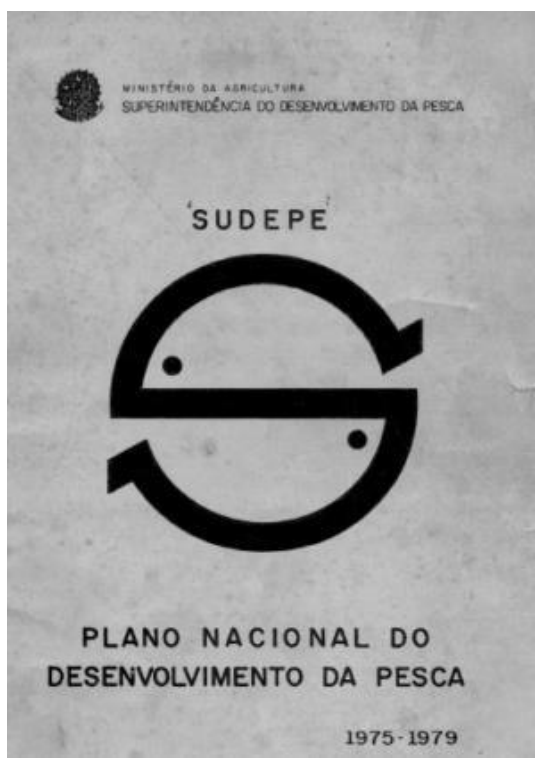


Avaliar o entendimento da SUDEPE sobre o desenvolvimento da pesca nos fornecerá importantes indicativos de como a instituição conduziu a atividade nesse período e direcionou sua política. Para esta autarquia, a evolução da política pesqueira está organizada em duas grandes fases: pré-industrial ou artesanal, e industrial. A primeira fase remonta a três subdivisões, que vão desde os primeiros atos legais da pesca, a exemplo da criação da Capitânia dos Portos, pela Marinha do Brasil em 1846, passando pela fase institucionalização da pesca, através do projeto de nacionalização da Marinha e, por fim, o período de tecnificação, com a Divisão de Caça e Pesca do Ministério da Agricultura. O período que ora analisamos, está incluído na segunda fase, "industrial", subdivida em dois períodos: a consolidação da industrialização e a ampliação dos incentivos fiscais para o fomento da pesca industrial.

\section{Quadro 1. A "evolução do setor pesqueiro"}

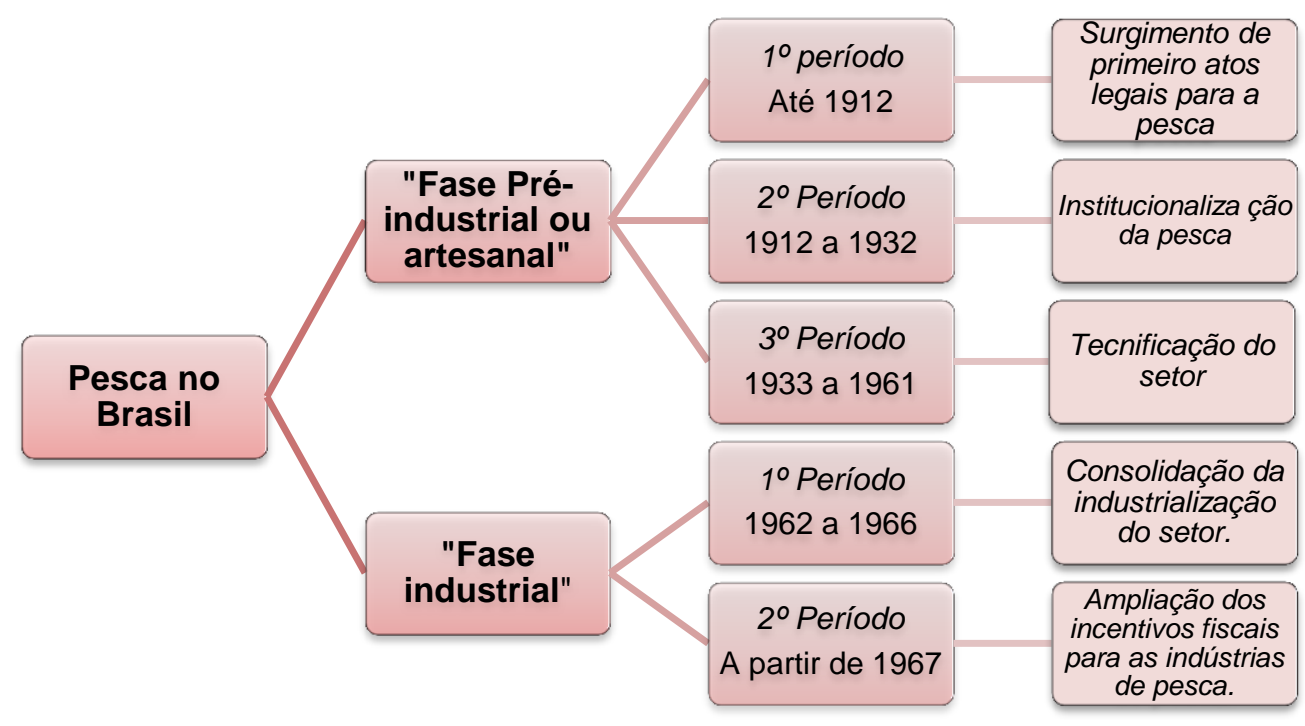

Fonte: Cyrino (2018). Esquema organizado a partir de consulta às informações do Plano Nacional de Desenvolvimento da Pesca 1975 - 1979, elaborado pela SUDEPE (1980).

Essa divisão do desenvolvimento da pesca já demarca a atividade artesanal como algo superável, parte de um processo evolutivo, distinguindo a fase de gestão da SUDEPE como algo superior a um período "pré-industrial” ou "artesanal". Esse entendimento é alentado no próprio Plano Nacional do Desenvolvimento da Pesca, ao descrever o primeiro período da fase industrial, de 1962 a 1966, no qual o governo se preocupou com a promoção da industrialização da pesca e a modernização das atividades pesqueiras. Vejamos no quadro a seguir: 


\section{Quadro 2. O tradicional como atraso: a fase industrial da pesca, pela SUDEPE}

Nesse período, torna-se expressiva a preocupação governamental de promover o desenvolvimento industrial, não só através da ativação dos programas de investimentos públicos e privados, mediante o aperfeiçoamento de instrumentos clássicos e a criação de novos estímulos às empresas de capital aberto, mas também pela ativação de programas visando à modernização de ramos tradicionais onde prevaleciam relações de produção obsoletas e incompativeis com as exigências atuais de aumento de produtividade, economias de escala e racionalização administrativa (grifo nosso).

Fonte: Trecho extraído do Plano Nacional de Desenvolvimento da Pesca, 1975-1979 (SUDEPE, 1980:17, grifou-se).

Essas medidas adotadas pela SUDEPE supervalorizaram a indústria pesqueira, e com isso, os benefícios fiscais alcançavam somente as empresas, e estas concentraram seus projetos na construção e importação maciça de barcos, equipamentos e infraestrutura de terra, aumentando consideravelmente o controle dos meios de produção (Silva, 2015). Diegues (1995) elucida como esse sistema passou a vigorar:

[...] essa forma de se combinar os meios de produção e a força de trabalho está articulada e é dependente da produção empresarial-capitalista que lhe compra a produção e usa sua força de trabalho excedente, como tripulantes de grandes barcos de pesca. Nesse sentido, o setor é usado como um bolsão de força de trabalho barata para o setor empresarial-capitalista (Diegues, 1995:94, grifou-se).

No curso dessa trajetória, a SUDEPE passou a ter muitas atribuições, em especial com o volume de subsídios. Nesse cenário de expansão industrial surgiu a necessidade de organização do setor. Em 1963, através do Decreto 51.868, foi criado o Grupo de Trabalho para propor diretrizes a fim de promover o desenvolvimento da pesca no país e orientar as ações da SUDEPE:

\section{Quadro 3. O Decreto 51.868 de 1963, menção a pesca artesanal}

CONSIDERANDO que o desenvolvimento da pesca, em termos industriais, poderá constituir-se em poderosa fonte de riqueza nacional e proporcionar elementos capazes de suprir o mercado de consumo de produtos protéicos a baixo custo;

CONSIDERANDO a necessidade de melhor aparelhar as indústrias relacionadas com a pesca, bem como as embarcações que compõem nossa ainda incipiente frota pesqueira;

CONSIDERANDO que as condições de abandono em que vive o nosso pescador exigem do Governo a adoção de uma política de assistência técnica, econômica e social compatível com o progresso desse setor.

\section{Objetivos $\left(\right.$ Art. $\left.1^{\circ}\right)$}

Expandir os atuais índices de produção do pescado, para abastecer o País de proteína animal mais barata que a carne bovina, destinando os contingentes disponíveis deste produto ao mercado internacional (inciso, I);

Proporcionar, ao contingente humano empenhado na pesca artesanal, padrão de vida compatível com as possibilidades remunerativas da atividade, mediante a reorganização das colônias de pescadores e a instituição do sistema cooperativo (inciso VI).

Fonte: Trechos extraídos do preâmbulo e Art. $1^{\circ}$ do Decreto 51.868 de 27 de março de 1963, grifou-se (Brasil, 1963). 
Esse decreto nos chama atenção desde o seu preâmbulo, ao apresentar um panorama da pesca no período, destacando o seu potencial industrial, como fonte de riqueza para o país, apontando a necessidade ainda de dar suporte às indústrias pesqueiras.

Examinando este dispositivo legal com atenção é possível verificar o distanciamento do pescador artesanal do grupo industrial, ao considerar o contingente humano empenhado na pesca artesanal, ou seja, aqueles que ainda praticavam as técnicas artesanais. Do mesmo modo, a expressão padrão de vida compatível com as possibilidades remunerativas da atividade, revela a desvalorização dessa prática pesqueira comparando-a com os lucros das técnicas modernas de pesca. Por fim, mediante a reorganização das colônias de pescadores $e$ a instituição do sistema cooperativo, reforça o papel tutelar das colônias na melhoria da qualidade de vida dos pescadores artesanais. Neste cenário, a pesca recebe a classificação: comercial, desportiva e científica.

\section{Quadro 4. Classificação da Pesca pelo Código de Pesca, de 1967}

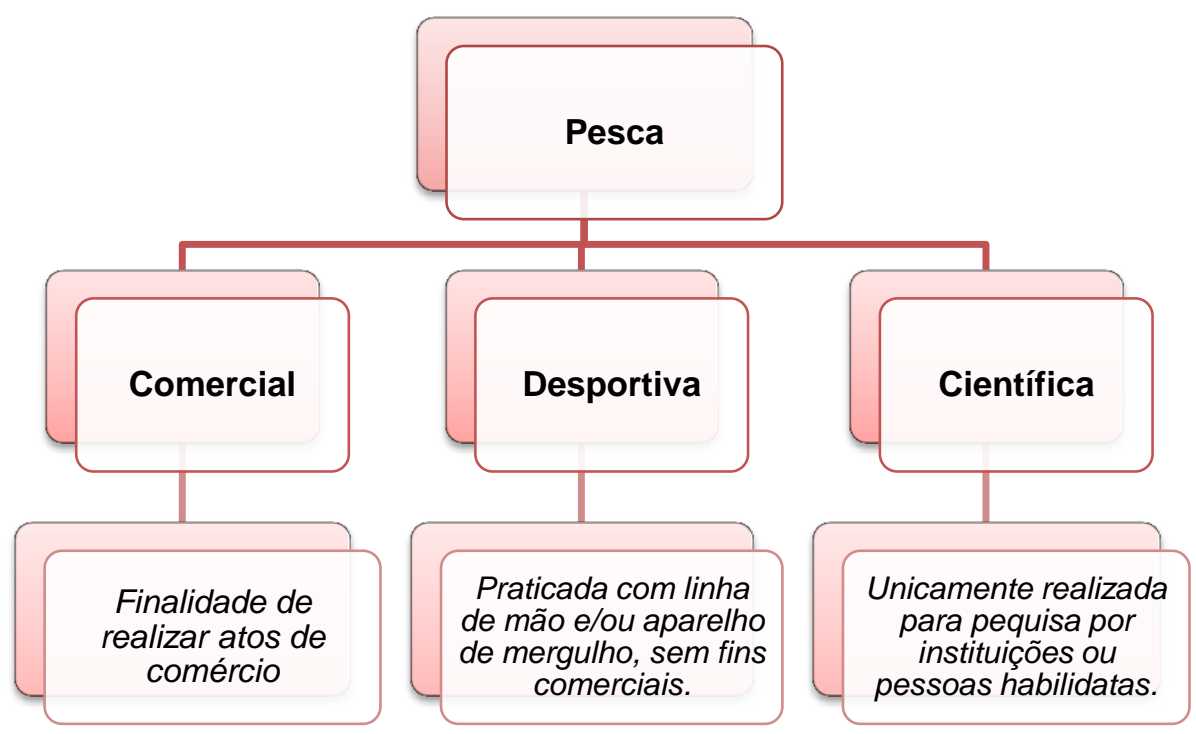

Fonte: (Cyrino, 2018). Consulta ao Decreto-Lei 221 de 28 de fev. de 1967 (Brasil, 1967).

Nesta reformulação, percebe-se que a divisão da pesca se deu pela finalidade da atividade pesqueira. Não há uma distinção da pesca de pequeno porte das atividades ligadas a indústria pesqueira. A atividade artesanal é desconsiderada. Essa orientação visava a atender ao projeto de transformar a atividade pesqueira em uma indústria de base no país e, dessa forma, a pesca artesanal encontrava-se desabrigada nesse Código. O referido Decreto-lei também classificava o que seria denominada empresas pesqueiras e pescadores profissionais, vejamos: 
Art. 18. Para os efeitos deste Decreto-lei define-se como "indústria da pesca", sendo conseqüentemente declarada "indústria de base", o exercício de atividades de captura, conservação, beneficiamento, transformação ou industrialização dos seres animais ou vegetais que tenham na água seu meio natural ou mais freqüente de vida.

Art. 26. Pescador profissional é aquele que, matriculado na repartição competente segundo as leis e regulamentos em vigor, faz da pesca sua profissão ou meio principal de vida (Brasil, 1967).

Percebemos no art. 26 como a categoria de pescador passa a ser identificada na legislação como aquela que, no desenvolvimento da atividade da pesca, esteja submetido à regulação do Estado, através da colônia. Revela-se a marcação de um ideário de controle das atividades (trabalho e resultados da produção) como de subordinação. Desdobramentos da investida militar naval que reforçou o caráter tutelar assumido pelas colônias.

Almejava-se ainda, a criação de uma pesca empresarial-capitalista no Brasil, através do fomento a incentivos fiscais, objetivando o retorno de recursos para o setor e, nesse direcionamento, a SUDEPE negligenciou também a pesca de pequeno porte (Diegues, 1983). A produção empresarial-industrial procedia em considerável parte dos próprios pescadores artesanais, através do sistema de compra da produção nos portos. Nesse sentido, reforça-se o caráter de transformar o pescador em força braçal das empresas pesqueiras:

Largando a pequena pesca à própria sorte, o objetivo do Decreto-lei no .221 de 1967 era claro: atribuir à pequena pesca a função de um bolsão de força de trabalho barata para a frota empresarial-capitalista que ao mesmo tempo se apropriara do pescado do setor mais dinâmico da pequena pesca (a produção dos pescadores artesanais motorizados) através do domínio da comercialização (Diegues, 1983:147).

No mesmo regulamento, a pesca desportiva tratava sobre a atividade sem fins lucrativos, exercida por pescadores amadores, destinada para atividades de lazer. Por fim, a pesca científica referia-se a atividade de pesquisa, e neste Código já sinalizava o interesse do Estado na promoção dos estudos sobre o ambiente marinho.

No Plano Nacional do Desenvolvimento da Pesca, a SUDEPE (1980) faz críticas a sua própria gestão, apontando o despreparo da instituição no cumprimento das suas atribuições e a necessidade de uma melhor definição dos seus objetivos.

Em todo o período considerado [da criação da autarquia, em 1962, até 1971], a SUDEPE não definiu claramente os seus objetivos gerais e específicos e não tendo fixado estes não poderia jamais elaborar planos e programas nacionais, da mesma forma como não se estruturou de forma adequada ao cumprimento das suas finalidades (Sudepe, 1980:20). 
O relatório do PNDP ainda discrimina quatro áreas que apresentaram debilidades na gestão: a de pesquisa, de incentivos fiscais, de assistência técnica e assistencial ao pescador. A primeira foi prejudicada devido à falta de controle das pesquisas pesqueiras que, consequentemente, eram desenvolvidas sem diretrizes, atendendo a interesses de outras entidades; já na de incentivos fiscais, a falta de habilidade levou a instituição à aprovação de centenas de projetos, sem uma política de planejamento; na área de assistência técnica, carecia de definição de conteúdo e, por fim, na área assistencial, "[...] vinha sendo executada de forma incipiente e precária, sendo que as atividades de revenda e financiamento se encontravam praticamente paralisadas" (Sudepe, 1980:22).

Diante desses problemas identificados, a SUDEPE viu a necessidade de reformular suas diretrizes. Em 1974 é editado o Decreto 73.632 que dispôs sobre a estrutura da instituição e indicaria as suas competências. Ao analisarmos o documento, é possível verificar a forte promoção da tecnificação da pesca a fim de atender os interesses da modernização do setor. O quadro a seguir destaca os principais eixos norteadores da SUDEPE, a partir desse novo regulamento:

\section{Quadro 5. A tecnificação da pesca}

Realizar pesquisas, objetivando a avaliação, a preservação dos recursos, o conhecimento da biologia e ecologia dos seres vivos aquáticos, os métodos e técnicas de cultivo nas águas territoriais, e modernização de técnicas de captura, industrialização e comercialização do pescado;

Prestar assistência técnica aos empreendimentos de pesca, oferecendo-lhes informações pertinentes às modernas técnicas de captura, conservação e industrialização do pescado;

Promover o treinamento e a formação de mão-de-obra especializada;

Prestar assistência sócio-profissional aos pescadores, estimulando a sua integração ao sistema cooperativista.

Fonte: (Cyrino, 2018). Consulta ao Decreto 73.632 de 13 de fevereiro de 1974 (Brasil, 1974). 
Além de enfatizar a importância da qualificação dos pescadores para suprir a demanda da indústria de pesca, o decreto também promove a pesquisa no setor a fim de explorar novos métodos de pesca e a preservação dos recursos marinhos. Quanto à assistência aos pescadores, o dispositivo legal direciona as colônias, através do sistema de cooperativas, a fim de que os mesmos possam gerar rendimentos que supram suas necessidades. A promoção de pesquisas no setor, fomentada nesse regulamento, irá impulsionar o desenvolvimento da aquicultura. Ocorre que, o impulso aos incentivos fiscais de forma desordenada, somada a expansão das indústrias de pesca e seu poder de captura, geraram a redução dos recursos pesqueiros ${ }^{6}$. Desse modo, a SUDEPE começa a voltar a sua atenção para a preocupação com a diminuição da exploração das espécies e, em 1983, é publicada a primeira legislação referente ao período de defeso $^{7}$ através da Portaria $n^{\circ} 50$, proibindo anualmente a pesca de espécies de camarões e definindo sanções no caso de descumprimento (Brasil, 1983a). No decorrer da década de 1980, outras portarias seriam publicadas, regulando também a pesca de arrasto ou de embarcações fechadas em determinadas regiões já com baixa produção, como a portaria $\mathrm{n}^{\circ} 51$ que proibia a "[...] a pesca de arrasto nas baías, lagoas costeiras, canais e desembocaduras de rios (estuários) em Santa Catarina” (Brasil, 1983b).

Nessa dinâmica, a fiscalização da SUDEPE orientou-se de forma classista (Ramalho, 2014), preterindo a atividade artesanal em benefício do grupo ligado à indústria pesqueira, ao apontar a primeira como causa dos impactos ambientais decorrentes da pesca, o que desdobrará na marginalização da pesca artesanal posteriormente. Mais do que isso, a SUDEPE fomentou a expansão das empresas de pesca, promovendo a subordinação e pobreza dos pescadores artesanais, o que acarretaria em graves consequências que perduram até hoje:

A Sudepe cumpriu um papel importante para o capital: viabilizar a expansão da pesca enquanto um negócio moderno e rentável para um grupo de empresários, criando, ao mesmo tempo, uma força de trabalho [os pescadores artesanais] disponível, ora permanente, ora de reserva (Ramalho, 2014:50).

Com uma gestão conturbada por exacerbado uso de incentivos fiscais e de crédito, a SUDEPE é extinta em 1989. Nesse contexto, em breve exposição, o regime ditatorial chega ao fim, no ano de 1985, após vinte e um anos no poder. Com a redemocratização do país e o

\footnotetext{
${ }^{6}$ Esse período de escassez dos recursos pesqueiros será acompanhado de políticas voltadas a questão ambiental e uma forte fiscalização direcionada ao pescador artesanal, através da regulação pelo IBAMA.

7 "Defeso é uma medida que visa proteger os organismos aquáticos durante as fases mais críticas de seus ciclos de vida, como a época de sua reprodução ou ainda de seu maior crescimento. Dessa forma, o período de defeso favorece a sustentabilidade do uso dos estoques pesqueiros e evita a pesca quando os peixes estão mais vulneráveis à captura, por estarem reunidos em cardumes" (Ministério do Meio Ambiente, 2017).
} 
advento da Constituição da República Federativa do Brasil, em 1988, os pescadores artesanais passam a ser incluídos no setor rural informal, e a as colônias são equiparadas a sindicatos de trabalhadores rurais, sendo livres a associação profissional ou sindical, o que irá propulsionar a criação de novas entidades representativas de pesca, como as Associações de Pescadores.

O projeto de nacionalização da pesca, através desse ousado plano de criação de uma empresa-capitalista no Brasil, com o objetivo de transformar a atividade pesqueira em uma indústria de base, fracassou. Houve o grande endividamento devido ao uso desmedido de subsídios e acentuou-se a escassez de espécies. Nesse âmbito, a desnacionalização da pesca deu-se tanto pela iniciativa de multinacionais na compra de algumas fábricas de pesca "como também pela política de joint - ventures, pelas quais empresas brasileiras se associam às estrangeiras para a exploração de recursos pesqueiros" (Maldonado,1986:36).

Nesse cenário, o projeto nacional-desenvolvimentista já estava em crise ${ }^{8}$ devido, entre outros fatores, ao endividamento ${ }^{9}$ do país e a eclosão de vários problemas sociais que afetavam diretamente as populações pobres. Somada a essas situações, a expansão desse projeto de desenvolvimento ocorreu sem qualquer preocupação com expressões territoriais tradicionais ${ }^{10}$ ou mesmo com preceitos ambientais. De fato, revela-se que a modernização que figurou como estandarte desse projeto de desenvolvimento nacional não tinha o objetivo de alcançar a todos, sobretudo os mais pobres. Ao contrário, promoveu a desigualdade social, a explosão de bolsões de pobreza, segregação socioespacial e, em contrapartida, gerou a acumulação de capital para grupos privilegiados. Silva (2004) traz uma análise que sintetiza bem esse direcionamento adotado:

[...] o pacto desenvolvimentista nunca se orientou no sentido de romper a herança do padrão de exploração colonial. Padrão este que tem por traço fundamental um formato perverso de institucionalização do conflito distributivo e de incorporação de massas. Em sua essência, sua dinâmica consiste em que as classes proprietárias absorvem os frutos da modernização econômica que promovem, excluindo a maioria da população (Silva, 2004:77, destaque da autora).

\footnotetext{
8 “[...] embora tenha ocorrido um extraordinário desenvolvimento capitalista, sobretudo a partir do final dos anos 60 e nos 70, não foi modificado o padrão básico de relações Estado/sociedade. Com isso, a partir de meados dos anos 70, e a sobreposição das crises externas que tem lugar nessa década, o pacto desenvolvimentista revelou de forma aguda seus limites e suas fragilidades até então contornados vias "reciclagem" da ordem política. As possibilidades de o Estado prosseguir como articulador do desenvolvimento capitalista nacional foram postas em xeque" (Silva, 2004:78).

${ }^{9} \mathrm{O}$ desenvolvimento econômico implementado no regime militar, o chamado milagre brasileiro, "ocultava sua fase sombria: o endividamento sem precedentes na história do Brasil, do Estado brasileiro. O capital internacional, um dos principais interessados na política econômica adotada pelos militares, também foi protagonista no crescimento da dívida externa do país" (Lemos, 2015:185).

${ }^{10}$ Apenas no ano de 2007 foi regulada, através do decreto 6.040, de 07 de fevereiro de 2007, a Política Nacional de Desenvolvimento Sustentável dos Povos e Comunidades Tradicionais.
} 
A expansão desordenada da indústria de pesca não somente comprometeu os territórios pesqueiros e os nascedouros de espécies, como também a reprodução dos modos de vida e trabalho dos pescadores e das suas comunidades. Sua força de trabalho foi reservada às empresas pesqueiras, através da desvalorização da sua atividade, na apropriação da força de trabalho, dos meios de produção e dos recursos pesqueiros, transformando os pescadores artesanais em meros "coadjuvantes" do setor (Ramalho, 2014). Havia uma clara diferenciação entre os pescadores que pescavam pequenas quantidades, muitas vezes para sua subsistência e de sua família e aqueles "patrões de pesca", que possuem grandes embarcações e estavam ligadas ao lucro da indústria pesqueira.

Esses direcionamentos mostram que, mesmo com diferentes órgãos responsáveis pela regulação da pesca, as escolhas da política de Estado nos períodos analisados priorizaram a abordagem modernizadora do setor (em prol do seu desenvolvimento técnico/industrial), sob a justificativa de impulsionar a economia do país. Paralelo a isso, as ações políticas voltadas para a pesca artesanal são burocratizadas e alheias à realidade dos pescadores e para obter acesso as mesmas observam-se, ainda, as marcas da condução tutelar do Estado, centralizada nas colônias de pescadores.

\section{Considerações finais}

A regulação pela SUDEPE reforçou a modernização, tecnificação e industrialização do setor, através de subsídios, orientados pelo modelo nacional-desenvolvimentista. Fomentou-se a apropriação tanto dos territórios e recursos pesqueiros, como também da força de trabalho dos pescadores. Esses direcionamentos além de priorizar a pesca industrial como propulsora de desenvolvimento e crescimento econômico, preteriu a atividade artesanal, e não dispôs de incentivos a valorização do seu saber-fazer e de suas comunidades, inserindo os pescadores artesanais em condições de pobreza e desigualdade social. Uma modernização prometida, camuflada sob o discurso tutelar e de progresso do país. Não obstante, estava direcionada a atender aos interesses estatais e grupos que se beneficiariam com a tecnificação e modernização do setor pesqueiro. Os benefícios dessa modernização não alcançavam as populações pesqueiras.

No curso de todas essas ações estatais, o que fica evidente são mais ações de incentivo ao crescimento produtivo através da modernização do que de fato uma política pública que contemple as especificidades da pesca artesanal. Por que para contribuírem no desenvolvimento do país os pescadores artesanais deveriam despir-se dos seus saberes e 
modos de vida e trabalho? A lógica desenvolvimentista impõe a lógica economicista e excludente, nesta, os benefícios da modernização encontram-se reservados a atender grupos restritos, o crescimento do país estaria atribuído a valores e índices econômicos, investimentos do capital ou ainda mercado de consumo. Como iniciado pela Missão militar, com a criação das colônias de pesca, o tradicional seguiu sendo classificado como obsoleto e precário, substituível por técnicas consideras modernas e superiores, enquanto as políticas públicas seguiram burocratizadas e instáveis, inserindo os pescadores artesanais e suas comunidades a um perverso processo de segregação.

Evidencia-se que, embora o projeto político anunciado leve a considerar a possibilidade de integração dos pescadores ao projeto de desenvolvimento nacional, seja por adesão a técnicas de modernização da atividade, seja pelos auxílios econômicos e sociais, as tramas subjacentes revelaram um processo perverso de exclusão dessas populações pesqueiras que não contemplaram políticas sociais que atentassem as suas realidades e valorizassem seus modos de vida e trabalho como potência no desenvolvimento do país. Ao contrário, tais políticas modernizadoras serviram como justificativa para legitimar as desigualdades e aviltamentos desse grupo. Uma insistente tentativa de categorizar os pescadores artesanais como incapazes de contribuir para o desenvolvimento do país e para construção de políticas públicas. Uma classificação do tradicional como um não-lugar do moderno e do progresso, que resulta numa regulação que privilegiou setores industriais pesqueiros e atentou contra a atividade, como também na garantia dessas populações de reproduzirem-se socialmente.

\section{Referências}

BRASIL (1974), I Plano Nacional de Desenvolvimento 1972 - 1974. Brasília, Serviço Nacional de Informação.

BRASIL (1934), Decreto-lei $n^{o} 23.672$ de 2 de janeiro de 1934. Dispõe sobre a aprovação do Código de Caça e Pesca. Sistema de Consulta à Legislação do MAPA. Acesso em 23 de junho de 2016. Disponível em http://www.agricultura.gov.br/legislacao

BRASIL (1938a), Decreto-lei $n^{\circ} 794$ de 29 de outubro de 1938. Dispõe sobre a criação do Código de Pesca. Sistema de Consulta à Legislação do MAPA. Acesso em 23 de junho de 2016. Disponível em http://www.agricultura.gov.br/legislacao

BRASIL (1938b), Decreto-lei $n^{\circ} 794$ de 29 de outubro de 1938. Dispõe sobre a criação do Código de Pesca. Sistema de Consulta à Legislação do MAPA. Acesso em 11 de junho de 2016. Disponível em http://www.agricultura.gov.br/legislacao

BRASIL (1962), Lei Delegada $n^{\circ} 10$ de 11 de Outubro de 1962. Cria a Superintendência do Desenvolvimento da Pesca e dá outras providências. Sistema de Consulta à Legislação do MAPA. Disponível em http://www.agricultura.gov.br/legislacao - Acesso em 17 de agosto de 2016. 
BRASIL (1963), Decreto-lei n ${ }^{\circ} 51.868$ de 27 de Março de 1963. Dispõe sobre grupos de trabalho para a pesca. Sistema de Consulta à Legislação do MAPA. Acesso em 11 de junho de 2016. Disponível em http://www.agricultura.gov.br/legislacao

BRASIL (1967), Decreto-lei $n^{\circ} 221$ de 28 de fevereiro de 1967. Dispõe sobre a criação do novo Código de Pesca. Sistema de Consulta à Legislação do MAPA. Acesso em 11 de junho de 2016. Disponível em http://www.agricultura.gov.br/legislacao

BRASIL (1974), Decreto-lei $n^{\circ} 73.632$ de 13 de fevereiro de 1974. Dispõe sobre reformulação das diretrizes da SUDEPE. Sistema de Consulta à Legislação do MAPA. Acesso em 02 de julho de 2016. Disponível em http://www.agricultura.gov.br/legislacao

BRASIL (1983a), Portaria SUDEPE $n^{\circ} 50$ de 20 de Outubro de 1983. Define o período de defeso para a pesca de camarões. Sistema de Consulta à Legislação do MAPA. Acesso em 15 de agosto de 2016. Disponível em http://www.agricultura.gov.br/legislacao

BRASIL (1983b), Portaria SUDEPE $n^{\circ} 51$ de 26 de Outubro de 1983. Proíbe a pesca de arrasto em determinadas regiões. Sistema de Consulta à Legislação do MAPA. Acesso em 15 de agosto de 2016. Disponível em http://www.agricultura.gov.br/legislacao

BENTES FILHO, Giovanni R. P. (2018), Do Norte ao Sul. A Missão do Cruzador José Bonifácio e a incorporação do pescador a um projeto de nação (1900-1930). Dissertação. Natal: Programa de Pós-Graduação em História, Universidade Federal do Rio Grande do Norte. 181p.

CYRINO, Carolina O. S. C. (2018), “Aos pescadores, a modernidade!” Trajetórias da política pesqueira na regulação da pesca artesanal. Dissertação. Vitória: Programa de Pós-Graduação em Ciências Sociais, Universidade Federal do Espírito Santo. 162p.

CYRINO, Carolina O. S. C. (2019), Retornando ao arquivo colonial: vestígios civilizatórios na missão militar de instruir e sanear os pescadores brasileiros, in Anais do $18^{\circ}$ Congresso Brasileiro de Sociologia. Florianópolis.

CALlOU, Ângelo B. F. (1994), A voz do mar: construção simbólica da realidade dos pescadores brasileiros pela Missão do Cruzador "José Bonifácio" (1919-1924). São Paulo, Escola de Comunicação e Artes. Universidade Federal de São Paulo.

CARDOSO, Fernando H.; FALETTO, Enzo (1979), Dependência e desenvolvimento na América Latina. Ensaio de interpretação sociológica. 5. Ed. Rio de Janeiro, Zahar Editores.

CEPÊDA, Vera A. (2012a), História, periferia e política na obra de Celso Furtado, in Anais do $36^{\circ}$ Encontro Anual da ANPOCS. Caxambu.

CEPÊDA, Vera A. (2012b), "Inclusão, democracia e o novo-desenvolvimentismo: um balanço histórico". Revis. Estudos Avançados da Universidade de São Paulo, São Paulo, 26 (75), pp. 77-90.

COSTA, Sérgio (2017), "A pesquisa sobre modernidade na América Latina", in C. E. Sell, C. B. Martins (Orgs.), Teoria Sociológica Contemporânea: Autores e perspectivas. São Paulo, Annablume.

DIEGUES, Antonio C. (1983), Pescadores, camponeses e trabalhadores do mar. São Paulo, Ática.

DIEGUES, Antonio C. (1995), Povos e mares: leituras em sócio-antropologias marítimas. São Paulo, NUPAUB-USP.

FURTADO, Celso (1986), O mito do desenvolvimento econômico. Rio de Janeiro, Paz e Terra. 
GARCÍA-CANCLINI, Nestor (2015), Culturas hibridas. Estratégias para entrar e sair da modernidade. 4 ed. São Paulo, EDUSP.

LEMOS, Amarildo M. (2015), "Modernização econômica e conflito social no Espírito Santo na década de 1980", in L. C. M. Ribeiro et. al. (Orgs.), Modernidade \& Modernização no Espírito Santo. Vitória, Edufes, 2015.

MALDONADO, Simone C. (1986), Pescadores do mar. São Paulo, Ática.

MARINI, Ruy M. (2000), Dialética da dependência. Uma antologia da obra de Ruy Mauro Marini. Petropolis, Vozes.

MINISTÉRIO DO MEIO AMBIENTE (2017), Período de defeso. Biodiversidade [Consult. 12-012017]. Disponível em http://www.mma.gov.br/biodiversidade/biodiversidade-aquatica/recursospesqueiros/per\%C3\%ADodos-de-defeso

RAMALHO, Cristiano W. N. (2014), "Pescadores, Estado e desenvolvimento nacional: da reserva naval à aquícola". Revista do Centro de Estudos Rurais da UNICAMP, v. 8, n.1, pp. 31-62.

SANTOS, Leonardo B. (2015), "A modernidade chega de navio: aspectos do desenvolvimento do Espírito Santo pelo viés da expansão portuária", in C. M. R. Luiz (Org.), Modernidade e modernização no Espírito Santo. Vitória, Edufes.

SANTOS, Theotônio dos (1991), "Economia política da dependência", in T. Santos, Democracia e socialismo no capitalismo dependente. Petrópolis, Vozes.

SILVA, Marta Z. (2004), A Vale do Rio Doce na estratégia do desenvolvimentismo brasileiro. Vitória, EDUFES.

SIQUEIRA, Maria P. S. (2010), "Os grandes projetos industriais: desenvolvimento econômico e contradições urbanas", in M. P. S. Siqueira (Org.), Desenvolvimento brasileiro: alternativas $e$ contradições. Vitória, Grafitusa.

SUDEPE. (1980), Plano Nacional de Desenvolvimento da Pesca (1975 - 1979). Brasília, Ministério da Agricultura. 


\begin{abstract}
This work analyzes some of the modernization of fisheries process aspects in Brazil and their relation to the artisanal activity segregation, in the management of the former Superintendência de Desenvolvimento da Pesca - SUDEPE (Fisheries Development Superintendence), in the 1970s. During this period, the national-developmental ideal reached the national economy, and in the fishing policies, they get strengthened through modernization strategies and fishing industries fomentation. In this study, we will analyze some of the SUDEPE strategies and discourses - using the legislation and institutional documents - in the development of modernization policies that had the promise of a "fisheries evolution", even if deprecating the artisanal fishing in the national development process.
\end{abstract}

Keywords: National-developmentalism; Modernization; Fisheries Policy; Artisanal fishing.

\title{
Resumen
}

Este artículo analiza aspectos del proceso de modernización de la pesca en Brasil y su relación con la segregación de la actividad artesanal, durante la gestión de la extinta Superintendência de Desenvolvimento da Pesca - SUDEPE (Superintendencia de Desarrollo Pesquero), en la década de 1970. En este período, los ideales de desarrollo nacional alcanzaron la economía y la política nacional. En la actividad pesquera se fortalecieron mediante estrategias para modernizar y fomentar las industrias. Analizaremos algunas estrategias y discursos de SUDEPE - a través del análisis de documentos institucionales y disposiciones legales - en el desarrollo de políticas modernizadoras que tenían como promesa la "evolución del sector pesquero", sin embargo, descuidando la actividad artesanal en el proyecto de desarrollo nacional.

Palabras clave: Nacional-desarrollismo; Modernización; Política pesquera; Pesca artesanal. 